\title{
COMPARATIVE EFFICACY OF TEICOPLANIN AND CEFAZOLIN FOR CARDIAC OPERATION PROPHYLAXIS IN 3027 PATIENTS
}

Raphael Saginur, MD, FRCPC

Daniel Croteau, MScPharm ${ }^{\text {b }}$

Michel G. Bergeron, MD, FRCPC ${ }^{c}$

The ESPRIT Group*
Objective: Cephalosporins, especially cefazolin, are widely used in the prevention of postoperative wound infections after cardiac operations. As more and more Staphylococcus aureus and Staphylococcus epidermidis strains are becoming resistant to cephalosporins and other antibiotics, alternative agents, such as glycopeptides, are often used as prophylaxis. We performed a multicenter double-blind randomized controlled trial comparing teicoplanin, a glycopeptide antibiotic, with cefazolin.

Methods: A total of 3027 adult patients undergoing elective coronary artery bypass grafting, valve operations, or both were randomized to a single dose of teicoplanin $(15 \mathrm{mg} / \mathrm{kg}$ ) or a 2-day course of cefazolin ( $2 \mathrm{~g}$ initial dose, followed by $1 \mathrm{~g}$ every 8 hours for 6 more doses). Patients were followed up for a total of 6 months postoperatively. The primary objective was to compare, between groups, the incidence of surgical infections up to 30 days postoperatively. Secondary objectives were incidence of other infections, other complications, and death.

Results: A total of 3027 patients were randomized to receive either teicoplanin $(n=1518)$ or cefazolin $(n=1509)$. Thirty days postoperatively, there was a trend to more deep sternotomy wound infections in the teicoplanin group ( 31 vs $18, P=.087$ ), which became significant by 6 months (36 vs $19, P=.032$ ). One hundred percent of the gram-positive strains infecting patients were susceptible to teicoplanin, whereas $8.3 \%$ were resistant to cefazolin. Pneumonia and urinary tract infections were more common in the teicoplanin group. Deep wound infections of the leg were more common in the cefazolin group.

Conclusions: Cefazolin was more effective prophylaxis than teicoplanin against postoperative wound infections after elective cardiac operations. Infection rates were low with either treatment. (J Thorac Cardiovasc Surg 2000;120:1120-30)
From the Department of Medicine, The University of Ottawa, Ottawa, ${ }^{a}$ Infectious Diseases Research Center, Université Laval, Québec City, ${ }^{\mathrm{c}}$ and Aeterna Laboratory, Québec City, ${ }^{\mathrm{b}}$ Canada.

Supported by Hoechst Marion Roussel Canada Research Inc.

Presented in part at the 19th International Congress of Chemotherapy, Montreal, July 16-21, 1995.

Received for publication March 29, 2000; revisions requested May 15, 2000; revisions received July 7, 2000; accepted for publication July 18, 2000.

Address for reprints: Michel G. Bergeron, MD, FRCPC, Centre de Recherche en Infectiologie, Université Laval, CHUQ, Pavillon CHUL, 2705 Boul Laurier, Québec, QC G1V 4G2 Canada (Email: Michel.G.Bergeron@crchul.ulaval.ca).

*For members of the ESPRIT Group, see end of article.

Copyright (C) 2000 by The American Association for Thoracic Surgery

$0022-5223 / 2000 \$ 12.00+0 \quad \mathbf{1 2 / 1 / 1 1 0 3 8 4}$

doi:10.1067/mtc.2000.110384
$\Delta$ n estimated 760,000 cardiac surgical procedures were A performed in the United States in 1997, including 607,000 coronary bypass operations. ${ }^{1}$ In Canada there were over 18,000 coronary artery bypass graft (CABG) procedures in 1995-1996. ${ }^{2}$ In Europe 153,670 CABG procedures and 56,574 valve replacements were done in 1993. ${ }^{3}$ Infectious complications are a major source of morbidity and mortality postoperatively. The incidence of infection at the surgical sites, chest and leg, ranges from less than $1 \%$ to greater than $10 \%{ }^{4-6}$ and increases according to the severity of underlying disease. ${ }^{7}$ Infection ranges from superficial involvement of the wound to deeper soft tissue infection, sternal osteomyelitis, and mediastinitis, requiring surgical drainage and debridement, as well as antimicrobial therapy. 
Ten to thirty percent of cardiac surgical patients with deep wound infections die during their hospitalization. The duration of hospital stay is markedly prolonged by a mean of 12 to 16 days. ${ }^{8,9}$ The attributable cost is enormous, estimated at approximately $\$ 37,000$ in one American study or an increase of $180 \%$ over that of uninfected patients. ${ }^{4}$ Patients undergoing cardiac surgery are also at risk for the development of infections unrelated to the surgical site, such as pneumonia, urinary tract infection, and bacteremia, with the latter often related to line sepsis.

The most common pathogens associated with these infections are Staphylococcus epidermidis, Staphylococcus aureus, and gram-negative bacilli, such as Enterobacter species. ${ }^{10-12}$ Antibiotic prophylaxis is widely used to reduce the incidence of postoperative infection. Limited placebo-controlled data suggest that this prophylactic use of antimicrobials is efficacious in preventing infection at the surgical site. ${ }^{13}$ In North America the antibiotics of choice are cephalosporins. ${ }^{14}$ Cefazolin, cefamandole, and cefuroxime have been found to be safe and effective. ${ }^{15-19}$ There is no consistent advantage of one over the others. Vancomycin, the glycopeptide available in the United States and Canada, is widely used in patients with $\beta$-lactam allergy.

A high incidence of $\beta$-lactam-resistant $S$ epidermidis and a rising tide of methicillin-resistant $S$ aureus (MRSA) susceptible to vancomycin have raised interest in glycopeptides as prophylaxis in cardiac operations.

Doubts have been cast about the efficacy of a cephalosporin, cefazolin, in preventing infection caused by $S$ aureus. ${ }^{20}$ Furthermore, there has been concern about the selection or induction of resistance in organisms, such as coagulase-negative staphylococci and Enterobacter species, in cephalosporin recipients.

Two rigorous comparative studies have assessed the use of glycopeptides as prophylactic agents in cardiac operations. Wilson and colleagues ${ }^{21}$ compared teicoplanin with the combination of flucloxacillin and tobramycin in a total of 517 patients. Teicoplanin was less effective than the combination.

Maki and associates ${ }^{22}$ compared vancomycin with cefamandole and cefazolin in a population of 321 patients undergoing cardiovascular (mostly cardiac) operations. In that study vancomycin was more effective than the cephalosporins. However, hypotension was a significant complication of vancomycin, occurring in $8 \%$ of patients.

The ESPRIT study group sought to compare teicoplanin with cefazolin for cardiac operation prophylaxis. The pharmacokinetic properties of teicoplanin lend themselves to surgical prophylaxis. The drug has a long half-life, 130 to 166 hours with a 3-compartment model, allowing the use of a single high dose. ${ }^{23-25}$ The antibiotic is concentrated in cardiac tissue. ${ }^{26}$ Clearance of teicoplanin during cardiopulmonary bypass is similar to that found in nonsurgical patients. ${ }^{27}$ Unlike vancomycin, teicoplanin does not result in histamine release, which may cause rash and hypotension, and the drug can be given by means of rapid infusion without toxicity. ${ }^{28}$ It is less nephrotoxic than vancomycin. ${ }^{29}$

\section{Methods}

Design. This was a randomized controlled double-blind study done at 13 university-affiliated cardiac surgical centers across Canada. At each site, only the pharmacist was unblinded, and he or she was responsible for the distribution of drugs. The study nurses, surgeons, anesthetists, and physicians were unaware of each patient's prophylaxis regimen assignment. Randomization was done within 3 strata: CABG, valve replacement-repair, or both. The randomization was generated for each site by an independent statistician using a computer-generated list.

Patients. Adult ( $\geq 18$ years of age) patients undergoing elective CABG, valve operations (replacement or repair), or both were eligible for the trial. An elective operation was defined as a procedure planned at least 24 hours ahead. A signed written informed consent was obtained from each patient. Blood counts, serum creatinine levels, and urine cultures were procured. At each center, there was approval by the local research ethics board.

Exclusion criteria included the following: patients who were pregnant and those who had previously undergone sternotomy procedures; patients with severe concomitant diseases, such as the immunocompromised; patients who were morbidly obese; and individuals with osteotomies. Medically unstable patients and those with ventricular assist devices and/or requiring intra-aortic balloon pumps, transplant, or total artificial hearts were not enrolled. Patients who had received systemic antibiotics in the preoperative week and those allergic to glycopeptides, penicillins, or cephalosporins were not eligible. Active bacterial infections precluded entry into the study, but asymptomatic bacteriuria was allowed. Patients with serum creatinine levels of $250 \mu \mathrm{mol} / \mathrm{L}$ or more $(2.8 \mathrm{mg} / \mathrm{dL})$ or neutropenia of 1000 cells $/ \mathrm{mm}^{3}$ or less were excluded. Use of an investigational drug or device in the 30 days before the operation was not allowed nor was prior participation in a trial with teicoplanin. Patients of mental capacity so limited as to preclude informed consent were not enrolled.

An outbreak of MRSA occurred at one study center during the course of the study. Enrollment was interrupted at that site for the duration of the outbreak and then resumed.

Drug administration. Teicoplanin or cefazolin was packaged in 50-mL bags of normal saline solution to be infused over 15 minutes. Teicoplanin was given as a single preoperative dose of $15 \mathrm{mg} / \mathrm{kg}$ within 30 minutes of initial skin incision at the donor site or sternum, followed by placebo (normal saline solution, $50 \mathrm{~mL}$ ) every 8 hours for 6 more doses. 
Cefazolin was administered as a 2 -g preoperative dose, followed by $1 \mathrm{~g}$ every 8 hours for 6 more doses. The preoperative dose of study drug was covered with an opaque container to prevent identification of infusate in the bag, with teicoplanin solution being yellow-brown in color.

Assessment. Patients were seen by the research team before their operations, the first postoperative day, and at least 3 times weekly until discharge.

There was a follow-up visit or telephone contact of all patients at 30 days and 6 months postoperatively. All patient assessments and interpretations of patient outcomes were done before the data were unblinded.

Date of onset of infection was defined as the day of first physician visit or culture for the infectious illness or the date of readmission for infection, whichever came first.

Definitions were made before the onset of the study for important infectious syndromes relevant to the study:

1. Superficial thoracic wound infection: cellulitis, with systemic signs of infection, and/or purulent wound discharge (spontaneous or by aspiration)

2. Deep thoracic infections

A. Deep wound infection: wound infection requiring drainage and/or debridement

B. Sternal osteomyelitis: a deep sternal wound infection with evidence of bony infection (gross appearance, histopathology, and/or culture of bone) at operation for infection

C. Mediastinitis: a deep sternal wound infection with evidence of mediastinal involvement (gross appearance, histopathology, and/or culture) documented at operation for infection

D. Endocarditis: at least 2 of the following: (1) compatible clinical illness with evidence of cardiac involvement or no evidence of extracardiac source; (2) at least 2 positive blood cultures for the same organism; and (3) microbiologic or histopathologic evidence of valvular infection at reoperation or at autopsy

E. Pericarditis: infection of the pericardium defined at the operation and/or by aspiration

3. Donor site infections

A. Superficial donor site infection: cellulitis, with systemic signs of infection, and/or purulent wound discharge (spontaneous or by aspiration)

B. Deep donor site infection: wound infection requiring drainage and/or debridement

4. Bacteremia: at least one positive blood culture for a gram-negative microorganism or 2 positive blood cultures for the same gram-positive bacterium

5. Respiratory tract infections

A. Pneumonia. Definite: presence of a consistent syndrome (eg, fever or cough), infiltrate on chest x-ray film, and positive cultures of respiratory secretions (expectorated sputum showing less than 10 squamous epithelial cells per low-power field and more than 25 polymorphonuclear leukocytes per highpower field). Probable: purulent sputum ( $>25$ polymorphonuclear neutrophils per high-power field) plus an atypical infiltrate on chest $\mathrm{x}$-ray film. Possible: atypical infiltrate

B. Tracheobronchitis: cough and purulent sputum in the absence of an infiltrate on chest x-ray film

6. Urinary tract infections: greater than $10^{5}$ colonyforming units per milliliter in a cleanly voided specimen. In the presence of asymptomatic bacteriuria caused by the same organism preoperatively, the urinary tract infection was considered not attributable to the intervention and not counted

Definitions for other infections were based on those proposed by Pirsch and Maki. ${ }^{30}$

Objectives. The primary objective of the study was to compare the efficacy of single-dose teicoplanin with multiple-dose cefazolin in the prophylaxis of surgical infections 1 month after elective cardiac operations.

Secondary objectives were to compare both drugs in the prevention of surgical infections at the time of hospital discharge and 6 months postoperatively; to compare both drugs in the prevention of nonsurgical infections, noninfectious complications, and mortality at discharge, 1 month, and 6 months after the operation; to compare the microorganisms responsible for infections after operations; and to compare the safety of the 2 drugs.

Sample size estimation. The sample size was based on a surgical infection rate of approximately $2 \%$ among participating centers on the basis of informal surveys, which is consistent with literature reports in the $1 \%$ to $10 \%$ range. With a significance level of 5\% and a power of $80 \%$ and using a 2sample $\chi^{2}$ test, this required 1239 patients per arm.

Safety monitoring committee. Interim analysis was performed by an independent safety monitoring committee, consisting of a methodologist, a statistician, and a pediatric infectious disease specialist. Three analyses were performed (ie, one each after 600, 1200, and 1800 patients). The criterion for statistical significance was modified because of the 3 interim analyses.

\section{Results}

Of 12,198 individuals screened for inclusion into the study, 8973 were ineligible, 3225 were eligible, and 178 withdrew before their operation or their operation was canceled. Twenty others withdrew for other reasons. A total of 3027 were randomized: 1518 received teicoplanin, and 1509 received cefazolin.

Patient demographics are outlined in Table I. There was no significant difference between groups in sex, age, race, weight, severity of heart disease, or duration of preoperative stay. The number of patients with diabetes was similar in both arms of the study.

A similar proportion in either group underwent CABG only, a valve operation only, or a combined procedure.

Perioperative data are outlined in Table II. Mean preoperative stay in both groups was 1 week. Drugs were administered a mean of 42 minutes before incision in 
Table I. Patient demographics

\begin{tabular}{|c|c|c|c|}
\hline Parameters & Teicoplanin $(n=1518)$ & Cefazolin $(n=1509)$ & $\mathrm{P}$ value \\
\hline Male sex, n (\%) & $(79.9)$ & $1206(9.9)$ & NS \\
\hline Female sex, n (\%) & $304 \quad(20.1)$ & $303(20.1)$ & NS \\
\hline Age, y $($ mean \pm SD) & $61.6 \pm 10.2$ & $61.4 \pm 10.2$ & NS \\
\hline Weight, $\mathrm{kg}($ mean $\pm \mathrm{SD})$ & $78.0 \pm 13.9$ & $78.9 \pm 14.6$ & NS \\
\hline Coronary artery disease, $\mathrm{n}(\%)$ & $1339 \quad(88.2)$ & $1313(87.4)$ & NS \\
\hline Angina pectoris, $\mathrm{n}(\%)$ & $(87.9)$ & $1307(86.6)$ & NS \\
\hline Class III or IV, n (\%) & $(60.7)$ & 931 (61.7) & NS \\
\hline Prior myocardial infarction, n (\%) & $(47.3)$ & $716(47.4)$ & NS \\
\hline Valvular heart disease, n (\%) & $334 \quad(22.0)$ & $334(22.1)$ & NS \\
\hline Ejection fraction (mean $\pm \mathrm{SD})$ & $55.6 \pm 14.5$ & $55.0 \pm 14.3$ & NS \\
\hline Congestive heart failure, $\mathrm{n}(\%)$ & $270 \quad(17.8)$ & $290(19.1)$ & NS \\
\hline \multicolumn{4}{|l|}{ Race } \\
\hline White, n (\%) & $(96.2)$ & $1449(96.0)$ & NS \\
\hline Other, n (\%) & $(3.8)$ & $59 \quad(4.0)$ & NS \\
\hline Diabetes, n (\%) & (18.9) & $300(19.9)$ & NS \\
\hline \multicolumn{4}{|l|}{ Type of operation } \\
\hline CABG, n $(\%)$ & $(81.7)$ & $1227(81.3)$ & NS \\
\hline Valve repair-replacement, n (\%) & $(12.5)$ & $198(13.1)$ & NS \\
\hline $\mathrm{CABG}$ and valve repair-replacement, $\mathrm{n}(\%)$ & $(5.9)$ & $84 \quad(5.6)$ & NS \\
\hline
\end{tabular}

NS, Not significant.

Table II. Perioperative patient data

\begin{tabular}{|c|c|c|}
\hline Parameters & Teicoplanin & Cefazolin \\
\hline Duration of preoperative stay, $d$ (mean \pm SD) & $7.4 \pm 11.6$ & $7.3 \pm 11.5$ \\
\hline Drug exposure before incision, min (mean $\pm \mathrm{SD}$ ) & $42.0 \pm 18$ & $42.0 \pm 18$ \\
\hline Time in operating room, $\mathrm{h}($ mean $\pm \mathrm{SD})$ & $4.4 \pm 1.0$ & $4.4 \pm 1.0$ \\
\hline Duration of operation, $\mathrm{h}($ mean $\pm \mathrm{SD})$ & $3.9 \pm 1.0$ & $3.9 \pm 1.1$ \\
\hline Time on bypass, $\mathrm{h}($ mean $\pm \mathrm{SD})$ & $1.5 \pm 0.6$ & $1.5 \pm 0.6$ \\
\hline Estimated blood loss, $\mathrm{mL}($ mean $\pm \mathrm{SD})$ & $786.9 \pm 592.9$ & $752.9 \pm 483.3$ \\
\hline Intra-aortic balloon pump required, $\mathrm{n}(\%)$ & $31.0(2.0)$ & $21.0(1.4)^{*}$ \\
\hline Providone skin preparation, $\mathrm{n}(\%)$ & $850.0(56.2)$ & $848.0 \quad(56.4)$ \\
\hline Chlorexidine skin preparation, $\mathrm{n}(\%)$ & $567.0(37.5)$ & $549.0 \quad(36.5)$ \\
\hline Operative site irrigation, $\mathrm{n}(\%)$ & $351.0(23.6)$ & $357 \quad(24.3)$ \\
\hline
\end{tabular}

*Not significant.

Table III. Cumulative number of infections at the surgical site

\begin{tabular}{|c|c|c|c|c|c|c|c|c|c|c|}
\hline & \multicolumn{3}{|c|}{ Hospital discharge } & \multicolumn{3}{|c|}{30 days postoperatively } & \multicolumn{3}{|c|}{6 months postoperatively } & \multirow{2}{*}{$\begin{array}{c}\text { Cumulative } \\
\text { number of } \\
\text { patients }\end{array}$} \\
\hline & Teicoplanin & Cefazolin & $\mathrm{P}$ value & Teicoplanin & Cefazolin & $\mathrm{P}$ value & Teicoplanin & Cefazolin & $\mathrm{P}$ value & \\
\hline Superficial sternal wound & 28 & 25 & NS & 71 & 44 & .015 & 80 & 50 & .011 & 130 \\
\hline \multicolumn{11}{|l|}{ Deep thoracic infections* } \\
\hline Total patients & 24 & 14 & NS & 31 & 18 & NS & 36 & 19 & .032 & 55 \\
\hline Deep wound & 18 & 12 & NS & 23 & 13 & NS & 24 & 14 & NS & 38 \\
\hline Sternal osteomyelitis & 6 & 0 & $.042 \dagger$ & 6 & 0 & $.042 \dagger$ & 7 & 0 & .024 & 7 \\
\hline Mediastinitis & 3 & 2 & NS & 4 & 4 & NS & 4 & 4 & NS & 8 \\
\hline Endocarditis & 0 & 0 & NS & 1 & 0 & NS & 4 & 0 & NS & 4 \\
\hline Pericarditis & 0 & 1 & NS & 0 & 1 & NS & 0 & 1 & NS & 1 \\
\hline
\end{tabular}

NS, Not significant.

*This category includes deep wound sternal osteomyelitis, mediastinitis, endocarditis, and pericarditis. One patient may have more than one deep thoracic infection. $\dagger$ Not significant because $P$ value required for significance was established at .0412 . 
Table IV. Differences between teicoplanin and cefazolin in rates of infection outside the thoracic surgical site

\begin{tabular}{|c|c|c|c|c|c|c|c|c|c|c|}
\hline & \multicolumn{3}{|c|}{ Hospital discharge } & \multicolumn{3}{|c|}{30 days postoperatively } & \multicolumn{3}{|c|}{6 months postoperatively } & \multirow{2}{*}{$\begin{array}{c}\text { Cumulative } \\
\text { number of } \\
\text { patients }\end{array}$} \\
\hline & Teicoplanin & Cefazolin & $\mathrm{P}$ value & Teicoplanin & Cefazolin & $\mathrm{P}$ value & Teicoplanin & Cefazolin & $\mathrm{P}$ value & \\
\hline \multicolumn{11}{|l|}{ Wound infections: donor site } \\
\hline Superficial & 29 & 29 & NS & 68 & 84 & NS & 86 & 97 & NS & 183 \\
\hline Deep & 1 & 8 & $.043^{*}$ & 4 & 9 & NS & 4 & 13 & $.047 *$ & 17 \\
\hline \multicolumn{11}{|l|}{ Respiratory tract infections } \\
\hline Definite pneumonia & 29 & 18 & NS & 29 & 20 & NS & 31 & 23 & NS & 54 \\
\hline Probable pneumonia & 12 & 4 & NS & 13 & 4 & NS & 14 & 4 & .35 & 18 \\
\hline Tracheobronchitis & 63 & 41 & .039 & 74 & 47 & .017 & 82 & 54 & .021 & 136 \\
\hline \multicolumn{11}{|l|}{ Other } \\
\hline Bacteremia & 14 & 8 & NS & 15 & 11 & NS & 18 & 11 & NS & 29 \\
\hline Urinary tract infections & 101 & 24 & .001 & 114 & 27 & .001 & 122 & 34 & .001 & 156 \\
\hline
\end{tabular}

$N S$, Not significant.

* Not significant because $P$ value required for significance was established at .0412 .

both groups. Duration of operations (3.9 hours) and time on cardiopulmonary bypass ( 1.5 hours) were the same in both arms. There was similar blood loss. An intra-aortic balloon pump was required in $2.0 \%$ of the teicoplanin group and $1.4 \%$ of the cefazolin group. Skin antisepsis was similar in both groups, with antiseptic agents being predominantly povidone-iodine and chlorhexidine. Fewer than a quarter of the wounds in either group were irrigated. Superficial sternal wound infection rates were identical at the time of hospital discharge but rose over the first postoperative month to 71 $(4.7 \%)$ in the teicoplanin arm and $44(3.0 \%)$ in the cefazolin arm $(P=.015)$. At 6 months, the cumulative number of infections was 80 and 50, respectively $(P=.011$; Table III $)$.

A total of 55 deep thoracic infections were documented over the 6-month period of observation: 36 in the teicoplanin group and 19 in the cefazolin group $(P=.032)$. After 30 days, the difference between rates (31 [2.1\%] vs 18 [1.2\%], respectively) was not statistically significant $(P=.087)$. Throughout the study, sternal osteomyelitis was noted exclusively in the teicoplanin arm (at 6 months of observation, 7 [0.5\%] vs $0, P=.024)$. There were more deep wound infections and more cases of endocarditis in the teicoplanin group. Rates of mediastinitis and pericarditis were similar in the 2 groups.

The proportion of patients with superficial infections of the donor site in the leg was similar in both groups (Table IV). There was a trend to more deep leg infections in the cefazolin group (9 [0.7\%] vs 4 [0.3\%] after 1 month and 13 [1.1\%] vs 4 [0.3\%] after 6 months; $P=.047)$. There was more pneumonia with teicoplanin. There was significantly more tracheobronchitis with teicoplanin at all time intervals.
Postoperative urinary tract infection was 4 times more common in the teicoplanin group.

Deep wound infections were found more commonly in men, in diabetic patients, in elderly patients, and in obese patients (Table V). Infections were also more common in patients with longer preoperative stays and longer surgical procedures. In both groups significant differences were observed only in patients with diabetes and in patients whose operations exceeded 4 hours. There were similar rates of infections associated with bypass grafts and valve procedures (Table VI). There were no significant differences among the 13 centers (data not shown).

Gram-positive bacteria caused 143 (74\%) of 191 wound infections, and gram-negative bacteria caused the other 48 (25\%) infections (Table VII). Of these, 83 of the gram-positive isolates were in teicoplanin recipients, and 60 were in those receiving cefazolin. Pathogens associated with the 7 cases of sternal osteomyelitis included coagulase-negative staphylococci $(\mathrm{n}=5)$, Proprionibacterium species $(\mathrm{n}=1)$, and Escherichia coli $(\mathrm{n}=1)$.

One hundred twenty-seven $(75 \%)$ respiratory isolates were gram-negative bacteria, 38 (22\%) were gram-positive bacteria, and $6(3 \%)$ were yeast. Approximately three quarters of the gram-negative respiratory isolates and two thirds of the gram-positive isolates originated from the teicoplanin arm of the study. In the urinary tract there were 14 gram-positive and 113 gram-negative isolates. Ninety-nine of the 113 gram-negative isolates were in the teicoplanin group.

Overall, more infections were caused by coagulasenegative staphylococci and gram-negative rods in the teicoplanin group. Enterococcal infections were more common in the cefazolin arm. Gram-positive isolates 
Table V. Risk factors associated with deep thoracic infections at 30 days postoperatively

\begin{tabular}{lccc}
\hline & Teicoplanin (\%) & Cefazolin (\%) & P value \\
\hline Sex & & & \\
$\quad$ Male subjects & 2.25 & 1.34 & .1775 \\
$\quad$ Female subjects & 1.34 & 0.67 & \\
$\quad \begin{array}{l}\text { Diabetic status } \\
\quad \text { Diabetes }\end{array}$ & 4.88 & 2.67 & $<.0001$ \\
$\quad$ No diabetes & 1.40 & 0.84 & \\
$\quad \begin{array}{l}\text { Age } \\
\quad \leq 65 \mathrm{y}\end{array}$ & 1.84 & 0.95 & .1755 \\
$\quad>65 \mathrm{y}$ & 2.45 & 1.65 & \\
Body mass index & & & \\
$\quad<27$ units & 1.82 & 1.13 & .4742 \\
$\quad>27$ units & 2.32 & 1.30 & \\
Operation duration & & & \\
$\quad<4 \mathrm{~h}$ & 1.12 & 0.55 & .0001 \\
$\quad>4 \mathrm{~h}$ & 3.49 & 2.24 & \\
Preoperative stay & & & \\
$\quad<5 \mathrm{~d}$ & 1.72 & 1.06 & .1099 \\
$\quad \geq 5 \mathrm{~d}$ & 2.87 & 1.55 & \\
$\quad$ Overall infection rate & 2.07 & 1.21 & \\
\hline
\end{tabular}

were all susceptible to teicoplanin. Eight percent of the gram-positive infections and $34 \%$ of the gram-negative infections were resistant to cefazolin (Table VIII). All teicoplanin wound infections were caused by grampositive bacteria, which were shown to be susceptible in vitro to teicoplanin. A similar observation was made with cefazolin in that all but 5 gram-positive isolates from surgical infections were sensitive to cefazolin. One hundred ninety-six gram-positive strains, including $82 S$ aureus, $84 S$ epidermidis, and 30 other Staphylococcus species (1 S hominis, 3 S capitis, $9 S$ haemolyticus, $12 S$ simulans, and $5 S$ warneri), were tested for the presence of the mec A gene by using a PCR primer (Table IX). ${ }^{21}$ There were 5 mec A-positive $S$ aureus (6\%) strains and $42 \mathrm{mec}$ A-positive $S$ epidermidis $(50 \%)$ strains. This resistance gene was not observed in the other staphylococcal species. Three $S$ epidermidis strains harbored this gene, and they were susceptible to oxacillin, as determined by standard phenotypic susceptibility testing. We were successful in inducing resistance in vitro to oxacillin in all of these strains.

Seventy (2.3\%) people died during this study (Table $\mathrm{X})$. There was no difference between groups in mortality rates in general or mortality rates attributed to infection $(0.9 \%$ for the teicoplanin arm and $0.82 \%$ for the cefazolin arm). There was no difference in severe circulatory disease postoperatively. Very few patients were lost to follow-up (Table X).
Table VI. Total deep thoracic infections by procedure* $^{*}$

\begin{tabular}{|c|c|c|c|c|c|}
\hline \multirow[b]{3}{*}{ CABG } & \multicolumn{5}{|c|}{$30 d$} \\
\hline & \multicolumn{2}{|c|}{ Teicoplanin } & \multicolumn{2}{|c|}{ Cefazolin } & \multirow{2}{*}{$\frac{\text { Total }}{39}$} \\
\hline & $26 / 1240$ & $(2.1 \%)$ & $13 / 1227$ & $(1.1 \%)$ & \\
\hline Valve & 2/89 & $(1.1 \%)$ & 3/198 & $(1.5 \%)$ & 5 \\
\hline CABG plus valve & $3 / 89$ & $(3.5 \%)$ & $2 / 84$ & $(2.4 \%)$ & 5 \\
\hline
\end{tabular}

*Differences between antibotic groups and procedures are not significant.

Duration of hospitalization postoperatively, which was 10 days in the teicoplanin group and 9.5 days in the cefazolin group, was similar, as was the duration of intensive care (Table XI). Three hundred twenty (21\%) members of the teicoplanin cohort were readmitted for acute or convalescent care compared with $20 \%$ of the cefazolin cohort. Deep thoracic infections exerted a profound influence on the duration of hospitalization (Table XII). Irrespective of prophylaxis groups, there was a 20-day prolongation of hospital stay in the infected patients.

A total of 157 adverse events in 106 patients were attributed to the study drugs, mostly nausea and vomiting. There was no difference between the 2 drug arms (Table XIII).

\section{Discussion}

In this study cefazolin provided more effective prophylaxis against superficial and deep surgical infections than teicoplanin. Notably, sternal osteomyelitis was observed only in the teicoplanin group. Urinary tract infection and tracheobronchitis were likewise significantly more common in teicoplanin recipients.

Infection was not associated with increased mortality in this group of patients. However, in both arms of the study, deep thoracic infections dramatically prolonged hospitalization by 20 days.

The $1.1 \%$ absolute difference in deep thoracic infections noted after 6 months of observation (ie, from $2.4 \%$ to $1.3 \%$ in the respective arms) is small. That there was a significant difference between groups reflects the statistical power of the study, which was the largest of its kind yet reported, and the 6-month period of observation, which allowed delayed surgical site infections to become manifest.

In view of the fact that this study was performed in 13 centers over a vast geographic area, it reflects more than a local idiosyncrasy of microbial flora. The nature of the glycopeptide-cephalosporin comparison is complex. Glycopeptides are more reliably active in vitro against staphylococci harboring the mec A gene, 
Table VII. Cause of infections

\begin{tabular}{|c|c|c|c|c|c|}
\hline \multirow[b]{3}{*}{ Sites } & \multirow[b]{3}{*}{ Total } & \multicolumn{4}{|c|}{ Gram-positive bacteria (n, teicoplanin/cefazolin) } \\
\hline & & \multicolumn{2}{|c|}{ Staphylococci } & \multirow[b]{2}{*}{ Enterococci } & \multirow[b]{2}{*}{ Other } \\
\hline & & Coagulase + & Coagulase - & & \\
\hline Deep thoracic wound infections & $26 / 19$ & $3 / 8$ & $22 / 6$ & $0 / 1$ & $1 / 4$ \\
\hline Superficial thoracic wound infections & $38 / 16$ & $11 / 3$ & $25 / 11$ & $1 / 2$ & $1 / 0$ \\
\hline Donor sites (deep and superficial) & $19 / 25$ & $8 / 15$ & $9 / 3$ & $1 / 3$ & $1 / 4$ \\
\hline Respiratory tract infections & $25 / 13$ & $17 / 7$ & $5 / 2$ & $0 / 0$ & $3 / 4$ \\
\hline Urinary tract infections & $1 / 13$ & $0 / 0$ & $0 / 4$ & $0 / 8$ & $1 / 1$ \\
\hline Bacteremia & $6 / 7$ & $0 / 5$ & $6 / 1$ & - & $0 / 1$ \\
\hline Total isolates & $115 / 93$ & $39 / 38$ & $67 / 27$ & $2 / 14$ & $7 / 14$ \\
\hline
\end{tabular}

Table VIII. Susceptibility of bacterial pathogens isolated from infected patients

\begin{tabular}{lccc}
\hline Gram status & & Teicoplanin & Cefazolin \\
\hline Gram positive $(\mathrm{n}=205)$ & Susceptible* & $205(100 \%)$ & $188(91.7 \%)$ \\
& Resistant $\dagger$ & 0 & $17(8.3 \%)$ \\
Gram negative $(\mathrm{n}=195)$ & Susceptible & ND & $128(66 \%)$ \\
& Resistant & ND & $67(34 \%)$ \\
\hline
\end{tabular}

$N D$, Not done; teicoplanin lacks gram-negative activity.

*Susceptible strains: teicoplanin MIC, $8 \mu \mathrm{g} / \mathrm{mL}$; cefazolin MIC, $8 \mu \mathrm{g} / \mathrm{mL}$.

$\dagger$ Resistant strains: teicoplanin MIC, $32 \mu \mathrm{g} / \mathrm{mL}$; cefazolin MIC, $32 \mu \mathrm{g} / \mathrm{mL}$.

NCCLS. Performance Standards for Antimicrobial Susceptibility testing; Fifth International Supplement. NCCLS Document M100-S5. Villanova (PA): NCCLS; 1994. Vol. 14, No. 16.

Table IX. Presence or absence of mec A gene in 196 staphylococcal species

\begin{tabular}{lccc}
\hline Strains & No. & mec A gene present & mec A gene absent \\
\hline S aureus & 82 & 5 & 77 \\
S epidermidis & 84 & $42(3)^{*}$ & 42 \\
Staphylococcus species & 30 & 0 & 30
\end{tabular}

*Three strains of $S$ epidermidis were susceptible to oxacillin, as determined by using Kirby-Bauer disk susceptibility testing, and had an mec A gene. We were successful in inducing resistance in vitro to oxacillin in these 3 strains.

notably $S$ epidermidis, and enterococci. Glycopeptides are more narrow in spectrum and should therefore be less of a disruption to the patient's endogenous flora.

Because $50 \%$ of the $S$ epidermidis strains isolated in our study were resistant to methicillin and harbored the mec A gene, the greater number of gram-positive surgical infections in the teicoplanin group was unexpected. Inexplicably, although $100 \%$ of the gram-positive pathogens isolated in our patients remained susceptible to teicoplanin in vitro, gram-positive bacteria were more common in the teicoplanin group than the cefazolin group in thoracic wound infections, both deep and superficial, as well as in respiratory tract infections. Of particular concern was the high proportion (6/7) of gram-positive infections among the patients with sternal osteomyelitis, all of which occurred in teicoplanin recipients. In leg incisions and in the urinary tract, there were more gram-positive infections in the cefazolin group than in the teicoplanin group.

On the basis of in vitro antimicrobial activity and pharmacokinetic data, teicoplanin appeared to be a very promising prophylactic agent for cardiac operations. Previous studies had shown that the ratio of teicoplanin concentrations (ie, cardiac tissue/serum) varied between 1.1 and 10 , which was higher than those obtained previously with fusidic acid (0.33), cloxacillin (0.73), cefamandole (0.35), cefazolin (0.23), and vancomycin (0.2-0.4). ${ }^{26,32}$

Moreover, 24 hours after the preoperative infusion of a $12 \mathrm{mg} / \mathrm{kg}$ dose, which was less than the $15 \mathrm{mg} / \mathrm{kg}$ 


\begin{tabular}{ccccc} 
Total & Enterobacteriaceae & Nonfermenters & Other & Yeast(n, teicoplanin/cefazolin) \\
\hline $4 / 3$ & $3 / 3$ & $1 / 0$ & - & - \\
$7 / 2$ & $7 / 1$ & $0 / 1$ & - & - \\
$1 / 22$ & $8 / 20$ & $2 / 2$ & $58 / 19$ & $3 / 3$ \\
$96 / 31$ & $31 / 9$ & $7 / 3$ & $1 / 0$ & $3 / 0$ \\
$99 / 14$ & $95 / 13$ & $3 / 1$ & - & - \\
$9 / 1$ & $9 / 1$ & - & $59 / 19$ & $6 / 4$ \\
$225 / 73$ & $153 / 47$ & $13 / 7$ & & \\
\hline
\end{tabular}

Table X. Morbidity-mortality*

\begin{tabular}{lccc}
\hline End point & Teicoplanin $(n=1527)$ & Cefazolin $(n=1520)$ & P value \\
\hline Myocardial infarction & $40(2.6)$ & $34(2.2)$ & NS \\
Stroke & $19(1.2)$ & $20(1.3)$ & NS \\
Pulmonary embolism & $8(0.5)$ & $6(0.4)$ & NS \\
Death with ongoing infection & $14(0.9)$ & $12(0.8)$ & NS \\
Death (all) & $35(2.3)$ & $35(2.3)$ & NS \\
Lost to follow-up & $10(0.7)$ & $13(0.8)$ & NS \\
\hline
\end{tabular}

All values are given as number (\%).

*No differences were significant.

Table XI. Patient disposition postoperatively

\begin{tabular}{lcc}
\hline & Teicoplanin & Cefazolin \\
\hline Duration of postoperative hospitalization, d (mean \pm SD) & $10.0 \pm 7.9$ & $9.5 \pm 6.7$ \\
Time in ICU, d (mean \pm SD) & $3.21 \pm 3.81$ & $3.02 \pm 3.32$ \\
Need for ICU readmission, $\mathrm{n}(\%)$ & $52(3.4)$ & $49(3.3)$ \\
Hospital readmission, $\mathrm{n}(\%)$ & $320(21.1)$ & $297(19.7)$ \\
$\quad$ Nonconvalescent, $\mathrm{n}(\%)$ & $246(16.2)$ & $243(16.1)$ \\
Convalescent, $\mathrm{n}(\%)$ & $95(6.3)$ & $69(4.6)$ \\
Need for reoperation during hospitalization, $\mathrm{n}(\%)$ & $52(3.4)$ & $42(2.8)$ \\
\hline
\end{tabular}

used in this study, patients undergoing cardiac surgery had serum teicoplanin levels above the minimal inhibitory concentrations (MICs) for $90 \%$ of grampositive pathogens. Mean concentrations detected in heart tissue were 10 to 20 times higher than the MICs for $90 \%$ of methicillin-susceptible and methicillinresistant $S$ aureus and $S$ epidermidis, Enterococcus faecalis, and Corynebacterium jeikeium. This was in contrast to the concentration of vancomycin in heart tissue, which approximates the MIC for these organisms. Moreover, although maximum levels of cefamandole, cloxacillin, and flucloxacillin were 4 to 8 times higher than the MICs of these antibiotics against methicillin-susceptible bacteria, they were lower than the MICs for methicillin-resistant bacteria. The same applies for cefazolin. ${ }^{32}$

Interestingly, all the escape bacteremia (ie, bacteremia caused by microorganisms susceptible to antimicrobials) associated with teicoplanin prophylaxis was caused by S epidermidis. In contrast, most of the cases of gram-positive pneumonia and tracheobronchitis were caused by $S$ aureus, against which teicoplanin has excellent in vitro activity.

Why was teicoplanin less effective than cefazolin against sternal wound infections? The kinetics of teicoplanin may have played against the drug. Teicoplanin is highly protein bound (ie, approximately $90 \%){ }^{33,34}$ Levels of free drug are relatively low, and 
Table XII. Influence of deep thoracic infections on duration of hospitalization

\begin{tabular}{|c|c|c|c|c|}
\hline & \multicolumn{2}{|c|}{ Infected } & \multicolumn{2}{|c|}{ Noninfected } \\
\hline & No. of patients & Mean duration (d) & No. of patients & Mean duration (d) \\
\hline Teicoplanin & 31 & $30.1(25.4)$ & 1466 & $9.6(6.5)$ \\
\hline Cefazolin & 18 & $27.2(18.2)$ & 1472 & $9.3(6.1)$ \\
\hline Total & 49 & $29.0 *$ & 2938 & $9.4^{*}$ \\
\hline
\end{tabular}

$* P<.001$.

Table XIII. Drug-related adverse events

\begin{tabular}{lcc}
\hline Adverse event & Teicoplanin $(n=1518)$ & Cefazolin $(n=1509)$ \\
\hline Nausea & $30^{*}$ & 22 \\
Vomiting & 12 & 11 \\
Rash & 4 & 3 \\
Hypotension & 3 & 5 \\
Anaphylactic shock & 1 & 1 \\
Total patients & 57 & 49 \\
Total events & $79 \dagger$ & 78 \\
\hline
\end{tabular}

*Number of patients reporting event.

$\dagger$ Number of adverse events.

activity is correspondingly reduced..$^{35,36}$ Although levels of teicoplanin are high in cardiac tissue, ${ }^{26}$ they are low in presternal subcutaneous fat. ${ }^{37}$ Teicoplanin penetrates sternal bone poorly. ${ }^{38}$ We attempted to overcome these negative features by using a high dose of teicoplanin (ie, $15 \mathrm{mg} / \mathrm{kg}$ ).

Furthermore, although glycopeptides, including teicoplanin, exhibit good in vitro activity against grampositive bacteria, as determined by MICs, these drugs are only slowly bactericidal compared with $\beta$-lactams. ${ }^{35}$ This may be an important detriment to activity in prophylaxis. Also, when compared with vancomycin, teicoplanin has only modest activity against $S$ epidermidis. ${ }^{39-42}$

Glycopeptides provide no activity against facultative gram-negative rods, which may cause operative and nonoperative site infections. A priori we were concerned about the potential for gram-negative infections in the teicoplanin group. This concern was realized in urinary and respiratory tract infections and in bacteremia. Of particular interest is the fact that there were more gram-negative deep and superficial donor site infections in the cefazolin group than in the teicoplanin arm and that these infections were due, for the most part, to cefazolin-susceptible enterobacteriaceae. For gram-negative infections at other sites, cefazolin provided effective prophylaxis, despite a $34 \%$ resistance rate of gram-negative pathogens to cefazolin in this study. With such high levels of resistance, one would have expected more gram-negative infections in the cefazolin group than those observed. The conventional concept of MIC may not be entirely applicable to prophylaxis. Other factors, such as rate of kill and inoculum effect, may also explain some of the apparent discrepancies observed here.

Previous studies have suggested that male sex, old age, obesity, and prolonged preoperative stay were determinant factors increasing the likelihood of infectious complications. In our present clinical trial, diabetes mellitus and the duration of operation appear as the only significant risk factors for the development of infections.

Adverse events in both groups were relatively uncommon and generally inconsequential. Of note, hypotension was not a problem with teicoplanin, occurring with similar frequency as with cefazolin. This supports the data of Sahai and associates, ${ }^{28}$ differentiating teicoplanin from vancomycin. Whereas vancomycin induces histamine release, teicoplanin does not.

This study was done in centers with a low prevalence of MRSA. Vancomycin would be indicated if MRSA were the predominant strain of $S$ aureus. One historically controlled study suggested equivalence of vancomycin and teicoplanin. A rigorous randomized controlled trial between these 2 drugs would be of great interest. Until that time, no definite statement can be made about the comparative efficacy of vancomycin and teicoplanin.

In conclusion, cefazolin provided more effective prophylaxis than teicoplanin in preventing postoperative infections after cardiac operations.

We thank Francis Martineau for expert performance of mec A gene detection.

\section{REFERENCES}

1. American Heart Association. Medical procedures, facilities and costs. Available from: http://www.americanheart.org/statistics/09medicl.html.

2. Heart and Stroke Foundation of Canada. The changing face of 
heart disease and stroke in Canada. Ottawa, Canada: Heart and Stroke Foundation of Canada; 1999. p. 54.

3. Unger F. Open heart surgery in Europe 1993. Eur J Cardiothorac Surg 1996;10:120-8.

4. Loop FD, Lytle BW, Cosgrove DM, et al. Sternal wound complications after isolated coronary artery bypass grafting: early and late mortality, morbidity, and cost of care. Ann Thorac Surg 1990;49:179-87.

5. The Parisian Mediastinitis Study Group. Risk factors for deep sternal wound infection after sternotomy: a prospective, multicenter study. J Thorac Cardiovasc Surg 1996;111:1200-7.

6. El Oakley RM, Wright JE. Post-operative mediastinitis: classification and management. Ann Thorac Surg 1996;61:1030-6.

7. Culver D, Gaynes R, and the National Nosocomial Infection Surveillance (NNIS) System. The standardized infection ratio: a new method of comparing surgical site infection (SSI) rates using the NNIS SSI Index. In: Proceedings of the Society for Healthcare Epidemiology Annual Meeting; 1994 Mar 20-22; New Orleans La. Abstract \#L3.

8. Kappstein I, Schulgen G, Fraedrich G, et al. Added hospital stay due to wound infections following cardiac surgery. Thorac Cardiovasc Surg 1992;40:148-51.

9. Nelson RM, Dries DJ. The economic implications of infection in cardiac surgery. Ann Thorac Surg 1986;42:240-6.

10. Miedzinski LJ, Keren G. Serious infections complications of open-heart surgery. Can J Surg 1987;30:103-7.

11. Andersen BM, Sorlie D, Hotvedt R, et al. Multiple beta-lactam resistant Enterobacter cloacae infections linked to the environmental flora in a unit for cardiothoracic and vascular surgery. Scand J Infect Dis 1989;21:181-91.

12. Flynn DM, Weinstein RA, Kabins SA. Infections with Gram-negative bacilli in a cardiac surgery intensive care unit: the relative role of Enterobacter. J Hosp Infect 1988;11(Suppl A):367-73.

13. Fong IW, Baker CB, McKee DC. The value of prophylactic antibiotics in aorto-coronary bypass operations: double-blind randomized trial. J Thorac Cardiovasc Surg 1979;78:908-13.

14. LoCicero J. Prophylactic antibiotic usage in cardiothoracic surgery. Chest 1990;98:719-23.

15. Slama TG, Sklar SJ, Misinski J, Fess SW. Randomized comparison or cefamandole, cefazolin, and cefuroxime prophylaxis in open-heart surgery. Antimicrob Agents Chemother 1986;29:744-7.

16. Kaiser AB, Petracek MR, Lea JW, et al. Efficacy of cefazolin, cefamandole and gentamicin as prophylactic agents in cardiac surgery. Ann Surg 1987;206:791-7.

17. Gentry LO, Zeluff BJ, Cooley DA. Antibiotic prophylaxis in open-heart surgery: a comparison of cefamandole, cefuroxime and cefazolin. Ann Thorac Surg 1988;420:167-71.

18. Doebbeling BN, Pfaller MA, Kuhns KR, et al. Cardiovascular surgery prophylaxis: a randomized, controlled comparison of cefazolin and cefuroxime. J Thorac Cardiovasc Surg 1990;99:981-9.

19. Townsend TR, Reitz BA, Bilker WB, Bartlett JG. Clinical trial of cefamandole, cefazolin, and cefuroxime for antibiotic prophylaxis in cardiac operations. J Thorac Cardiovasc Surg 1993;106:66470 .

20. Kernodle DS, Classen DC, Burke JP, Kaiser AB. Failure of cephalosporins to prevent Staphylococcus aureus surgical wound infections. JAMA 1990;263:961-6.

21. Wilson AP, Treasure T, Gruneberg RN, Sturridge MF, Ross DN. Antibiotic prophylaxis in cardiac surgery: a prospective comparison of two dosage regimens of teicoplanin with a combination of flucloxacillin and tobramycin. J Antimicrob Chemother 1988;21:213-23.

22. Maki DG, Bohn MJ, Stolz SM, et al. Comparative study of cefazolin, cefamandole, and vancomycin for surgical prophylaxis in cardiac and vascular operations: a double-blind randomized trial. J Thorac Cardiovasc Surg 1992;104:1423-34.

23. Carver PL, Nightingale $\mathrm{CH}$, Quintiliani R, et al. Pharmacokinetics of single and multiple-dose teicoplanin in healthy volunteers. Antimicrob Agents Chemother 1989;33:82-6.

24. Lam YW, Kapusnik-Uner JE, Sachdeva M, et al. The pharmacokinetics of teicoplanin in varying degrees of renal function. Clin Pharmacol Ther 1990;47:655-61.

25. Antony KK, Lewis EW, Kenny MT, et al. Pharmacokinetics and bioavailability of a new formulation of teicoplanin following intravenous and intramuscular administration to humans. J Pharm Sci 1991;80:605-7.

26. Bergeron MG, Saginur R, Desaulniers D, et al. Concentration of teicoplanin in serum and atrial appendages of patients undergoing cardiac surgery. Antimicrob Agents Chemother 1990;34: 1699-702.

27. Mini E, Mazzei T, Reali EF, et al. Pharmacokinetics of teicoplanin during cardiopulmonary bypass surgery. Int J Clin Pharmacol Res 1989;9:287-92.

28. Sahai J, Healy DP, Shelton MJ, et al. Comparison of vancomycinand teicoplanin-induced histamine release and "red man syndrome." Antimicrob Agents Chemother 1990;34:765-9.

29. Kureishi A, Jewesson PJ, Rubinger M, et al. Double-blind comparison of teicoplanin versus vancomycin in febrile neutropenic patients receiving concomitant tobramycin and piperacillin: effect on cyclosporin-A associated nephrotoxicity. Antimicrob Agents Chemother 1991;35:2246-52.

30. Pirsch JD, Maki DG. Infectious complications in adults with bone marrow transplantation and T-cell depletion of the bone marrow. Ann Intern Med 1986;104:619-31.

31. Martineau F, Picard FJ, Lansac N, et al. Multiplex PCR assays for the species-specific identification of S. aureus and S. epidermidis and the detection of association antibiotic resistance genes. 97th General Meeting of the American Society of Microbioligy; 1997. Abstract C-54, p. 129

32. Bryan CS, Smith CW, Sutton JP, et al. Comparison of cefamandole and cefazolin during cardiopulmonary bypass. J Thorac Cardiovasc Surg 1983;86:222-5.

33. Assandri A, Bernareggi A. Binding of teicoplanin to human serum albumin. Eur J Clin Pharmacol 1987;33:191-5.

34. Rowland M. Clinical pharmacokinetics of teicoplanin. Clin Pharmacokinet 1990;18:184-209.

35. Chambers HF, Kennedy S. Effects of dosage, peak and trough concentrations in serum, protein binding, and bactericidal rate on efficacy of teicoplanin in a rabbit model of endocarditis. Antimicrob Agents Chemother 1990;34:510-4.

36. Bailey EM, Rybak MJ, Kaatz GW. Comparative effect of protein binding on the killing activities of teicoplanin and vancomycin. Antimicrob Agents Chemother 1991;35:1089-92.

37. Wilson AP, Shankar S, Felmingham D, Treasure T, Gruneberg RN. Serum and tissue levels of teicoplanin during cardiac surgery: the effect of a high dose regimen. J Antimicrob Chemother 1989;23:613-7.

38. Martin C, Bourget P, Alaya M, et al. Teicoplanin in cardiac surgery: intraoperative pharmacokinetics and concentrations in cardiac and mediastinal tissues. Antimicrob Agents Chemother 1997;41:1150-5. 
39. Moore EP, Speller DC. In vitro teicoplanin-resistance in coagulase-negative staphylococci from patients with endocarditis and from a cardiac surgery unit. $J$ Antimicrob Chemother 1988;21:417-24.

40. Goldstein FW, Coutrot A, Sieffer A, Acar JF. Percentages and distributions of teicoplanin-and vancomycin-resistant strains among coagulase-negative staphylococci. Antimicrob Agents Chemother 1990;34:899-900.
41. Maugein J, Pellegrin JL, Brossard G, et al. In vitro activities of vancomycin and teicoplanin against coagulase-negative staphylococci isolated from neutropenic patients. Antimicrob Agents Chemother 1990;34:901-3.

42. Miro JM, Pomar JL, Claramonte X, et al. Vancomycin (Van) versus Teicoplanin (Tei) for Antibiotic Prophylaxis in Cardiac Surgery. 36th Interscience Conference on Antimicrobrial Agents in Chemotherapy; 1996 Sep 15-16; New Orleans [LA]. Abstract J161.

\section{ESPRIT* list of investigators}

\begin{tabular}{|c|c|c|c|}
\hline Institution & Investigator & Coinvestigator & Research coordinator \\
\hline $\begin{array}{l}\text { Hopital Laval/Laval University } \\
\text { Heart Institute, Quebec City }\end{array}$ & M. Bergeron, MD & $\begin{array}{l}\text { J. Metras, MD } \\
\text { S. Trottier, MD }\end{array}$ & $\begin{array}{l}\text { L. Fournier, R. Langlois, } \\
\text { L. LaPointe }\end{array}$ \\
\hline $\begin{array}{l}\text { Ottawa Civic Hospital/ } \\
\text { University of Ottawa } \\
\text { Heart Institute }\end{array}$ & R. Saginur, MD & W. Goldstein, MD & K. Drouin, D. Cooke \\
\hline $\begin{array}{l}\text { Institut de Cardiologie, } \\
\text { Montreal }\end{array}$ & P. Auger, MD & M. Carrier, MD & S. David, H. Creo \\
\hline $\begin{array}{l}\text { Victoria Hospital, } \\
\text { London }\end{array}$ & M. Myers, MD & & C. Clark \\
\hline Vancouver General Hospital & A. Chow, MD & G. Fradet, MD & K. Sleigh \\
\hline $\begin{array}{l}\text { Hôpital Sacré Cœur, } \\
\text { Montreal }\end{array}$ & Y. Girouard, MD & R. Baillot, MD & G. Gaudet, J. Fouquet \\
\hline $\begin{array}{l}\text { Hamilton General Hospital, } \\
\text { Hamilton }\end{array}$ & $\begin{array}{l}\text { I. Luchsinger, MD } \\
\text { S. J. Landis, MD }\end{array}$ & S. Brister, MD & L. Walker, L. Morrison \\
\hline $\begin{array}{l}\text { Montreal General Hospital, } \\
\text { Montreal }\end{array}$ & D. Portnoy, MD & J. Morin, MD & S. Shapiro \\
\hline $\begin{array}{l}\text { Royal Victoria Hospital, } \\
\text { Montreal }\end{array}$ & H. Robson, MD & B. de Varennes, MD & N. Fosset, K. Roy \\
\hline $\begin{array}{l}\text { Totonto General Hospital, } \\
\text { Toronto }\end{array}$ & I. Salit, MD & T. David, MD & S. Van Luven, S. Yake \\
\hline Victoria General Hospital & W. Schlech, MD & R. Landymore, MD & S. Hyndman, N. Meagher, D. Dickey \\
\hline $\begin{array}{l}\text { University of Alberta, } \\
\text { Edmonton }\end{array}$ & S. Shafran, MD & & S. McFadyen, S. Caouette \\
\hline $\begin{array}{l}\text { Health Science Centre, } \\
\text { Winnipeg }\end{array}$ & F. Aoki, MD & K. Duncan, MD & H. Peaters, T. Olafson \\
\hline
\end{tabular}

*Elective Sternotomy PRophylaxis of Infection with Teicoplanin. 